\title{
Study on Cost-Efficient Carbon Aerogel to Remove Antibiotics from Water Resources
}

\author{
Gülgün Aylaz, Meltem Okan, Memed Duman, and Halil Murat Aydin*
}

Cite This: ACS Omega 2020, 5, 16635-16644

Read Online

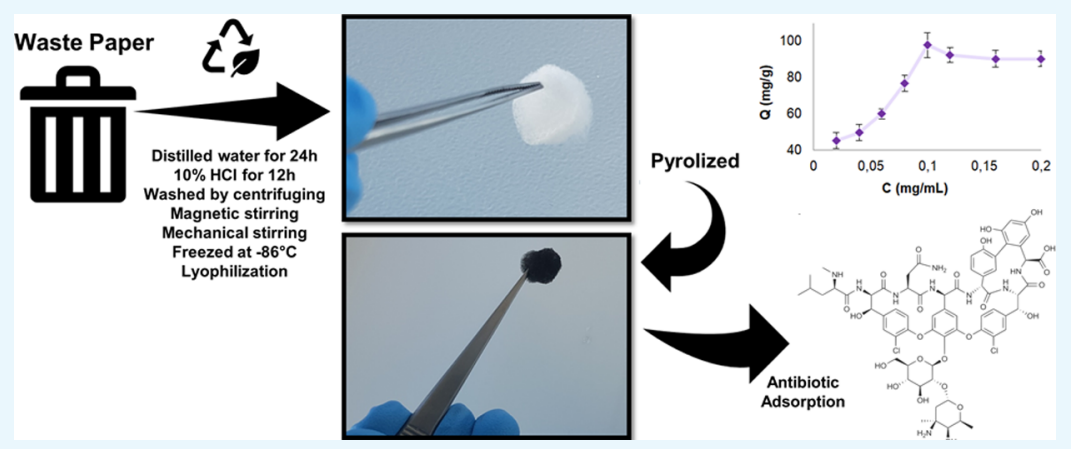

ABSTRACT: Because of pharmaceutical-emerging contaminants in water resources, there has been a significant increase in the antibiotic resistance in bacteria. Therefore, the removal of antibiotics from water resources is essential. Various antibiotics have been greatly studied using many different carbon-based materials including graphene-based hydrogels and aerogels. In this study, carbon aerogels (CAs) were synthesized from waste paper sources and their adsorption behaviors toward three antibiotics (hygromycin B, gentamicin, and vancomycin) were investigated, for which there exist a limited number of reports in the literature. The prepared CAs were characterized with scanning electron microscopy, transmission electron microscopy, X-ray photoelectron spectroscopy, and micro-computerized tomography $(\mu-\mathrm{CT})$. According to the $\mu$-CT results, total porosity and open porosity were calculated as 90.80 and $90.76 \%$, respectively. The surface area and surface-to-volume ratio were found as $795.15 \mathrm{~mm}^{2}$ and $16.79 \mathrm{~mm}^{-1}$, respectively. The specific surface area of the CAs was found as $104.2 \mathrm{~m}^{2} / \mathrm{g}$. A detailed adsorption study was carried out based on different $\mathrm{pH}$ values, times, and analyte concentrations. The adsorption capacities were found as 104.16, 81.30, and 107.52 mg/g for Hyg B, Gen, and Van, respectively. For all three antibiotics, the adsorption behavior fits the Langmuir model. The kinetic studies showed that the system fits the pseudo-second-order kinetic model. The production of CAs, within the scope of this study, is safe, facile, and costefficient, which makes these green adsorbents a good candidate for the removal of antibiotics from water resources. This study represents the first antibiotic adsorption study based on CAs obtained from waste paper.

\section{INTRODUCTION}

There is a growing interest toward the removal of pharmaceutical-emerging contaminants in water resources because of which there has been a notable increase in the antibiotic resistance in bacteria, obstructing the infection treatments. ${ }^{1-3}$ Accordingly, a great deal of hospital-acquired infections is due to these multidrug-resistant bacteria. ${ }^{4}$ Various pharmaceuticals are constantly being added to the latest contaminant candidate list of the United States Environmental Protection Agency (US-EPA) and the list is expected to grow. As the World Health Organization (WHO) defines, antibiotic resistance can occur naturally and affect anyone and threaten the global health. Using safe water is one of the key points to prevent the spread of it.

A number of antibiotics have been studied thus far. A common attention was paid mostly on quinolones such as ciprofloxacin, ${ }^{5,6}$ macrolides such as erythromycin, ${ }^{7}$ tetracyclines, ${ }^{8}$ nitroimidazoles such as metronidazole, ${ }^{2}$ and amox- icillin from the penicillin family. ${ }^{3}$ However, there exist more antibiotics from various other families that also need to be studied. Hygromycin B (Hyg B) is an aminoglycoside broadspectrum antibiotic with the molecular formula $\mathrm{C}_{20} \mathrm{H}_{37} \mathrm{~N}_{3} \mathrm{O}_{13}$ that acts against bacteria, fungi, and higher eukaryotic cells. Gentamicin (Gen) is another aminoglycoside broad-spectrum antibiotic consisting of four major and several minor components with the molecular formula $\mathrm{C}_{21} \mathrm{H}_{43} \mathrm{~N}_{5} \mathrm{O}_{7}$ and is used mostly against Gram-negative bacteria. Gen is also the most commonly used antimicrobial in the poultry production. ${ }^{9}$

Received: April 1, 2020

Accepted: June 19, 2020

Published: June 28, 2020 
Gen, along with several others, is the primary defence antibiotics used for treating Pseudomonas infections. ${ }^{10}$ Vancomycin (Van), on the other hand, belongs to the family of glycopeptides as a branched tricyclic glycosylated peptide. It is a broad-spectrum antibiotic with the molecular formula $\mathrm{C}_{66} \mathrm{H}_{75} \mathrm{Cl}_{2} \mathrm{~N}_{9} \mathrm{O}_{24}$, acting against methicillin-resistant strains of Staphylococcus aureus and is used for drug-resistant Grampositive bacteria. Pathogens with resistance against multiple classes of antibiotics are called superbugs and are especially crucial. Van-resistant Enterococci is one of the most wellknown superbugs, which makes Van removal from water resources a rather essential issue. ${ }^{11,12}$

There exist traditional techniques for the elimination of antibiotics from resources, such as using membranes, ${ }^{13,14}$ biodegradation, ${ }^{15}$ chemical oxidation, ${ }^{16}$ ionic treatment, ${ }^{17}$ and adsorption. $^{18,19}$ Among these techniques, adsorption is the most convenient technique because of adsorbents being easy to produce, rather cost-efficient, and quite effective. Carbonbased materials are extraordinary tools to be used as adsorbents and many examples can be found in the literature. $^{20-26}$ Carbon aerogels (CAs), carbon nanotubes (CNTs), and graphene aerogels (GAs) are high-surface-area materials most commonly produced with sol-gel chemistry. They are quite promising materials with unique mass-specific surface area, chemical inertness, and environmental compatibility. ${ }^{27}$ Some of the new structures are rather unfavorable because of their complicated and high-cost production and handling procedures together with several other drawbacks. For instance, the synthesis of graphene oxide (GO) yields a large amount of chemical waste, ${ }^{28-30}$ and CNT production usually requires further purification steps before use. Therefore, CAs are considerably easy to produce and handle. In the studies conducted thus far, CAs were most commonly used for the oil/water and oil/organic solvent separations. ${ }^{30-34}$

The amount of waste paper produced every single day is far beyond to be disregarded, which estimated around 400 million tons annually. ${ }^{35}$ This makes paper, among all other materials, the most widely produced and attainable type of waste in the world. In this study, CAs were produced from waste paper and employed for the antibiotic adsorption. The CAs were prepared inside 24-well plates (approximately $2 \mathrm{~cm}^{3}$ per well) and incubated in different antibiotic solutions (Hyg B, Gen, and Van). The antibiotic adsorptions were tested with a UV spectrophotometer. The proposed carbon adsorbent is easy to produce employing green chemistry, cost-efficient because of paper wastes being easily attainable, and has good adsorption capacity. This work, therefore, introduces a facile and practical synthesis route for CAs and represents the first study for their utilization in the removal of antibiotics from water resources.

\section{RESULTS AND DISCUSSION}

2.1. Characterization of CAs. The microstructural features and the morphology of the CAs were characterized with scanning electron microscopy (SEM) and transmission electron microscopy (TEM). The SEM image clearly showed that the thickness of fibers within the aerogel were more or less the same (Figure 1a). Figure $1 \mathrm{~b}$ shows an individual carbon fiber with a thickness of approximately $3.4 \mu \mathrm{m}$.

The chemical composition of the aerogel surface was studied with X-ray photoelectron spectroscopy (XPS). The obtained spectrum showed the C-to-O ratio as 25.31 for CAs (Figure S2). This ratio was found to be closer to those reported in the
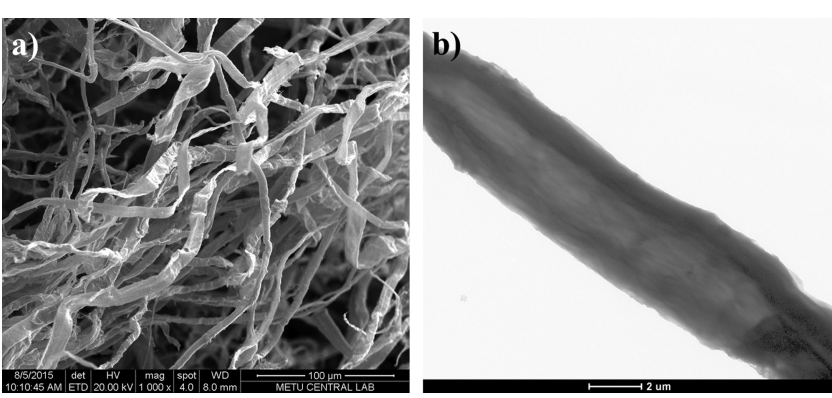

Figure 1. (a) SEM and (b) TEM images of the carbon material.

literature for carbon nanofiber aerogels, given as in the range of $14.13-20.55 .^{36}$ The quantity of elements $(\mathrm{C}, \mathrm{H}, \mathrm{N}$, and $\mathrm{S}$ ) in the produced materials was determined using an elemental analyzer (Figure S3). The $\mu$-CT system was used to reveal the 3D microstructural properties including open porosity, pore size, and pore distribution (Table S1). According to the results, total porosity and open porosity were calculated as 90.80 and $90.76 \%$, respectively. The surface area and surface-to-volume ratio were found as $795.15 \mathrm{~mm}^{2}$ and $16.79 \mathrm{~mm}^{-1}$, respectively. Finally, the connection density was found as $1.50 \mathrm{~mm}^{-3}$ (Table S1). Brunauer-Emmett-Teller (BET) surface area calculations were performed using an Autosorb $6 \mathrm{~B}$ surface area analyzer (Quantochrome Co., U.K.). The BET surface area was calculated as $104.2 \mathrm{~m}^{2} / \mathrm{g}$.

2.2. Adsorption Studies. Adsorption properties, such as adsorption capacity and rate, are important when high-surfacearea materials are employed as adsorbents in the elimination of materials because they reflect the adsorption capability, capacity, and reaction equilibrium velocity. First, in order to determine the effect of ambient $\mathrm{pH}$ on the adsorption of three antibiotics (Hyg B, Gen, and Van) by CAs, $\mathrm{pH}$ was changed between 2 and 9. As shown in Figure 2a, the highest antibiotic adsorption was observed at $\mathrm{pH} \mathrm{7,} \mathrm{6,} \mathrm{and} 3$ for Hyg B, Gen, and Van, respectively. The adsorbed antibiotic amounts at those particular $\mathrm{pH}$ values were 99.63, 58.83, and $102.33 \mathrm{mg} / \mathrm{g}$ for Hyg B, Gen, and Van, respectively.

Gen is an antibiotic used against $S$. aureus, which survives in acidic media. Studies on the antibiotic susceptibility of $S$. aureus at acidic $\mathrm{pH}$ showed that the activity of Gen was reduced when the environment was too acidic. ${ }^{37}$ In the study, the minimum inhibitory concentration of Gen was dramatically higher at $\mathrm{pH} 5.0$ than at $\mathrm{pH}$ 7.4. The observed effect was changing critically between $\mathrm{pH} 5.0$ and 6.0.

In our study, the experiment showed that the highest binding affinity was observed at $\mathrm{pH} 6$, which is within the safe range provided in the abovementioned study. The results of optimization conditions by Abdulmunim et al. showed that the highest antimicrobial activity of $\mathrm{Hyg} \mathrm{B}$ was obtained at $\mathrm{pH} 8$ at an incubation temperature of $35{ }^{\circ} \mathrm{C}$ for 10 days. ${ }^{38}$ Under these conditions, the toxicity of the Hyg B crude extract was examined in the liver of the mice, resulting in slight effects. The $\mathrm{pH}$ value at which the highest Hyg B adsorption was obtained matched with this value. Pauwels et al. in their study observed that the $\mathrm{pH}$ of Van solution showed a small change in the UV absorbance value at the end of $24 \mathrm{~h}$. Taking these observations into consideration, it was found that Van solution was physically stable for a period of $24 \mathrm{~h}$ and its activity was the maximum at $\mathrm{pH} 3.5 .{ }^{39}$ This value matches with the value at which the maximum binding capacity was observed in our study. 


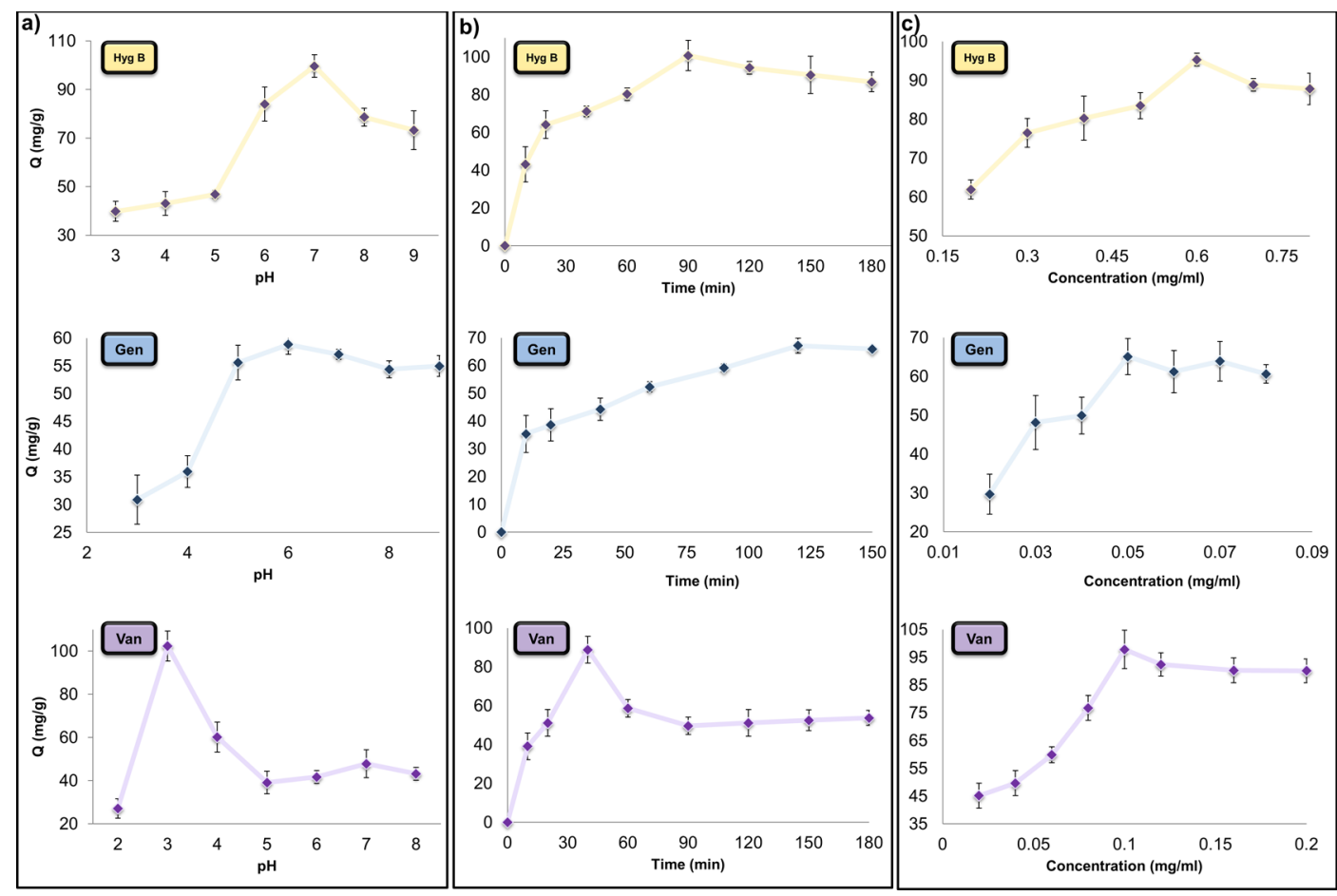

Figure 2. Effect of $(\mathrm{a}) \mathrm{pH},(\mathrm{b})$ time, and $(\mathrm{c})$ initial concentration on the adsorption capacity of antibiotics. In the pH studies, all experiments were conducted at room temperature for $3 \mathrm{~h}$ and the initial concentrations of antibiotics were $0.4,0.04$, and $0.04 \mathrm{mg} / \mathrm{mL}$ for Hyg B, Gen, and Van, respectively.

Table 1. Experimental Binding Capacity $\left(Q_{\text {exp }}\right)$ Found and Langmuir and Freundlich Constants Calculated for Hyg B, Gen, and Van

\begin{tabular}{|c|c|c|c|c|c|c|c|}
\hline & \multirow{2}{*}{$\frac{\text { experimental }}{Q_{\exp }(\mathrm{mg} / \mathrm{g})}$} & \multicolumn{3}{|c|}{ Langmuir constant } & \multicolumn{3}{|c|}{ Freundlich constant } \\
\hline & & $Q_{L}(\mathrm{mg} / \mathrm{g})$ & $B(\mathrm{~mL} / \mathrm{mg})$ & $R^{2}$ & $Q_{F}(\mathrm{mg} / \mathrm{g})$ & $n$ & $R^{2}$ \\
\hline Hyg B & 95.330 & 104.16 & 8.00 & 0.981 & 98.15 & 4.00 & 0.806 \\
\hline Gen & 65.079 & 81.30 & 8.79 & 0.926 & 97.53 & 2.35 & 0.733 \\
\hline \multirow[t]{3}{*}{ Van } & 97.822 & 107.52 & 31.00 & 0.964 & 177.15 & 2.88 & 0.830 \\
\hline & \multicolumn{4}{|c|}{$\mathrm{D}-\mathrm{R}$} & \multicolumn{3}{|c|}{ Temkin } \\
\hline & $Q_{m}(m g / g)$ & $B\left(\mathrm{~mol}^{2} / \mathrm{kJ}^{2}\right)$ & $E(\mathrm{~kJ} / \mathrm{mol})$ & $R^{2}$ & $K_{\mathrm{t}}(\mathrm{L} / \mathrm{g})$ & $b(\mathrm{~J} / \mathrm{mol})$ & $R^{2}$ \\
\hline Hyg B & 194.86 & 0.0029 & 13.130 & 0.8182 & 149.74 & 128.67 & 0.8115 \\
\hline Gen & 270.26 & 0.0046 & 10.425 & 0.755 & 66.52 & 125.66 & 0.7634 \\
\hline Van & 391.97 & 0.0028 & 13.363 & 0.836 & 338.59 & 106.76 & 0.7976 \\
\hline
\end{tabular}

Interaction time is important to understand the adsorption steps that affect the velocity of the whole process. Minimum amounts of time antibiotics reached their maximum adsorption by the aerogels were 90, 120, and 40 min for Hyg B, Gen, and Van, respectively (Figure $2 \mathrm{~b}$ ). The optimal interaction times for each antibiotic were determined and these interaction times were used in the subsequent concentration-scanning studies.

The effect of the initial concentration of the antibiotics on their adsorption amounts by the aerogels was investigated by changing the concentrations in aqueous solution in the range of $0.02-0.8 \mathrm{mg} / \mathrm{mL}$. This concentration scanning was made for each antibiotic, taking the optimal $\mathrm{pH}$ values and interaction times into account. Figure $2 c$ shows the effect of the initial concentrations of antibiotics on the adsorption capacities. As observed in the graphs, the amount of antibiotics adsorbed by the aerogels increased with increasing antibiotic concentration in the adsorption medium. The concentrations at which saturations were reached were found as $0.6,0.5$, and $0.1 \mathrm{mg} / \mathrm{mL}$ for Hyg B, Gen, and Van, respectively.
Next, the adsorption isotherms were investigated to find out which model fits the best to the adsorption behaviors toward the antibiotics. Using the correlation coefficients, it was found that for all three antibiotics, the adsorption behavior fits the Langmuir model (Table 1). This was determined by looking at the $R^{2}$ values, for which the one closest to 1 is assumed to be the fitting model. Table 1 shows that $R^{2}$ values for the Langmuir model are the highest. Moreover, the maximum adsorption values $\left(Q_{L}\right)$ meet the experimental ones $\left(Q_{\exp }\right)$. The Langmuir model assumes that the adsorbent has homogeneous binding sites with a single affinity constant value.

The Freundlich model is used to explain physical adsorptions taking place on the surface of heterogeneous adsorbents. In other words, it is assumed that each functional region on the surface of the adsorbent has a different adsorption potential. According to our findings, regions where adsorption events occur on the surfaces of the CAs have the same potential, making the system fit the Langmuir model. Because it fits the Langmuir model, equilibrium was 
Table 2. Pseudo-First-Order and Pseudo-Second-Order Kinetic Parameters Calculated From Kinetic Analyses of the Adsorption Studies for Three Different Antibiotics

\begin{tabular}{|c|c|c|c|c|c|c|c|c|}
\hline & \multirow{2}{*}{$\frac{\text { equilibrium }}{C(\mathrm{mg} / \mathrm{mL})}$} & \multirow{2}{*}{$\frac{\text { experimental }}{Q_{\exp }(\mathrm{mg} / \mathrm{g})}$} & \multicolumn{3}{|c|}{ pseudo 1st order kinetic } & \multicolumn{3}{|c|}{ pseudo 2 nd order kinetic } \\
\hline & & & $k_{1}(1 / \min )$ & $Q_{e}(\mathrm{mg} / \mathrm{g})$ & $R^{2}$ & $k_{2}(\mathrm{mg} / \mathrm{dL} \mathrm{min})$ & $Q_{e}(\mathrm{mg} / \mathrm{g})$ & $R^{2}$ \\
\hline Hyg B & 0.4 & 109.872 & 0.006679 & 5.281 & 0.432 & 0.115 & 96.154 & 0.987 \\
\hline Gen & 0.04 & 69.537 & 0.0150 & 4.870 & 0.814 & 0.077 & 72.463 & 0.991 \\
\hline \multirow[t]{6}{*}{ Van } & 0.04 & 94.812 & 0.0025 & 4.237 & 0.045 & 0.687 & 51.813 & 0.987 \\
\hline & & \multicolumn{7}{|c|}{ IPD } \\
\hline & & \multicolumn{3}{|c|}{$k_{\mathrm{i}}\left(\mathrm{g} \mathrm{mg}^{-1} \mathrm{~min}^{-0.5}\right)$} & \multicolumn{2}{|c|}{$C$} & \multicolumn{2}{|c|}{$R^{2}$} \\
\hline & Hyg B & \multicolumn{3}{|c|}{6.297} & \multicolumn{2}{|c|}{22.632} & \multicolumn{2}{|c|}{0.7889} \\
\hline & Gen & \multicolumn{3}{|c|}{4.5364} & \multicolumn{2}{|c|}{13.334} & \multicolumn{2}{|c|}{0.8903} \\
\hline & Van & \multicolumn{3}{|c|}{2.5944} & \multicolumn{2}{|c|}{29.882} & \multicolumn{2}{|c|}{0.2538} \\
\hline
\end{tabular}

proven to be reached at a constant temperature between the concentration of the environment and the concentration of the antibiotics that are adsorbed as single layers on the CAs which is assumed to be homogeneous. Because of the suitability to the Langmuir model, saturation of the adsorbent surface was also proven. Moreover, upon finding that the material had homogeneous structure, confirmation of the characterization was also established. ${ }^{40}$

The equilibrium data were also evaluated for the Temkin and Dubinin-Radushkevich (D-R) isotherm models (Table $1)$. Constants calculated and the average adsorption energy according to the $\mathrm{D}-\mathrm{R}$ adsorption isotherm give an idea regarding the physical and chemical nature of the adsorption process. Energy values for all antibiotics were found to be between 8 and $16 \mathrm{~kJ} \mathrm{~mol}^{-1}$; therefore, the adsorption process is believed to flow by chemical ion exchange. ${ }^{41}$ The Temkin constant $b$ is related with the adsorption heat; if it is positive, the reaction is exothermic and if it is negative, the reaction is endothermic. ${ }^{42}$ In this study, when the Temkin isotherm was analyzed, $b$ values were found positive. Although analyses were not performed at different temperatures, this finding may refer that the mechanism was endothermic.

System suitability to the Langmuir model proved the existence of homogeneous binding sites on the prepared CAs. Adsorption processes that fit this model have the advantage of "finite saturation limit", whereas because systems that fit the Freundlich model have heterogeneous binding sites, it is believed that the processes will be affected by the different environmental conditions. In the aqueous phase processes where the system does not fit both Langmuir and Freundlich, Temkin and $\mathrm{D}-\mathrm{R}$ models are used to find the suitable model. $^{40}$

When the correlation coefficients are examined, the interaction between the surface of the CAs and all three antibiotics seem to fit the pseudo-second-order kinetic model (Table 2). This was decided based on the $R^{2}$ and $Q_{e}$ values; for greater $R^{2}$ values $(0.991)$, the $Q_{e}$ values $(72.463 \mathrm{mg} / \mathrm{g})$ are closer to the experimental values $\left(Q_{\exp }\right)$ (69.537) (Figure S4). Also, the adsorption capacity values obtained from the pseudosecond-order kinetic model are in good agreement with the experimental results. When the kinetic data were analyzed, it was found that the adsorption of antibiotics to the carbon material was chemisorption without any diffusion restriction.

According to graphs drawn for the intraparticle diffusion (IPD) model which show no linearity, the $R^{2}$ values obtained were smaller than 1 . Therefore, it was found that the adsorption in our system was not at the intraparticle level (Table 2).
2.3. Comparison with Other Studies. As mentioned in the Introduction, the applications of CAs usually include oil removal or water-oil separation. ${ }^{30-34}$ In such studies, adsorption of crude oils or olive, cooking, or pump oils and organic solvents such as, benzene, acetone, chloroform, methanol, ethanol, $n$-hexane, cyclohexane, and so forth was studied. The adsorption of all these to CAs results in very high adsorption capacities. These very high values drop down dramatically to $\mathrm{mg} / \mathrm{g}$ levels when the studies are conducted upon antibody adsorption. Therefore, although the methods employed for the production of aerogel materials in the aforementioned work were found to be rather similar to what is done in this study, the comparison was made based on examples where the adsorbates were various antibiotics. In this sense, of course, the physical and chemical characteristics of the carbon materials differed significantly; however, a correlation was made in terms of their synthesis routes, surface area properties, and production challenges.

In a study carried out by Ma et al., adsorption capacities of graphene hydrogel (GH) and GA were compared using ciprofloxacin, a fluoroquinolone that show broad-spectrum antibacterial activity. ${ }^{43}$ It was found that the adsorption capacity of $\mathrm{GH}(235.6 \mathrm{mg} / \mathrm{g})$ was almost 6 times greater than that of GA $(42.2 \mathrm{mg} / \mathrm{g})$. It was also reported that the adsorption behavior fits the Langmuir model, which is similar to our findings. A further study conducted by the same group, based on GH and ciprofloxacin, provided a rather detailed comparison where different carbon-based materials from various other studies were synthesized and their adsorption capacities were determined. ${ }^{44}$ The highest capacity was found with GH $(235.64 \mathrm{mg} / \mathrm{g})$, followed by activated carbon (231 $\mathrm{mg} / \mathrm{g}$ ), CNT (135 mg/g), modified CNTs $(106-138 \mathrm{mg} / \mathrm{g}$ ), chemically prepared carbon $(104.2-133.3 \mathrm{mg} / \mathrm{g})$ through reduction of $\mathrm{GO}$ by aluminum powder, carbon xerogel (112 $\mathrm{mg} / \mathrm{g}), \mathrm{Fe}_{3} \mathrm{O}_{4} / \mathrm{C}(74.68 \mathrm{mg} / \mathrm{g}), \mathrm{GO} /$ calcium alginate fibers $(66.25 \mathrm{mg} / \mathrm{g})$, nano- $\mathrm{Fe}_{3} \mathrm{O}_{4}(12-37 \mathrm{mg} / \mathrm{g})$, and $\mathrm{GO} /$ magnetite composites $(10.91 \mathrm{mg} / \mathrm{g})$. These studies focused mostly on graphene-based materials; therefore, the interaction between the antibiotic and the material was based mainly on $\pi-\pi$ interactions. These interactions are of noncovalent types that involve $\pi$ systems where the electron-rich $\pi$ system can interact with a molecule or even another $\pi$ system. In the case of aromatic-aromatic interactions, which are also called $\pi$ stacking, the phenomenon results from the stacking of two aromatic groups just like in the case of graphene and ring structure of ciprofloxacin. In the article, the authors indeed indicated that the adsorption mechanism between the $\mathrm{GH}$ and ciprofloxacin was based on the $\pi-\pi$ electron donor-acceptor 
interaction, as well as some hydrophobic interactions and hydrogen bonding. In many other studies, this $\pi$-stacking has been accepted as the dominating force for the adsorption of organic molecules with benzene rings on the carbon surface. ${ }^{45-47}$ In our case, the synthesized CA showed no graphene characteristics; therefore, there were no $\pi-\pi$ interactions between the material and the adsorbate molecules chosen. Even in the absence of strong $\pi-\pi$ interactions, the material showed reasonable adsorption performance, yielding values of up to $107.52 \mathrm{mg} / \mathrm{g}$ for Van.

Another comparison at this point would be the uncomplicated and unsophisticated synthesis route. For instance, the bottom-up synthesis of GO can be done with chemical vapor deposition and epitaxial growth on silicon wafers, which need experience and are time-consuming. ${ }^{48}$ Its top-down syntheses include oxidation steps usually with $\mathrm{KClO}_{3}$, which produces toxic $\mathrm{ClO}_{2}$ gas. CNTs require purification, and other mentioned materials contain magnetic nanoparticles. Here, on the other hand, CAs can be synthesized using waste paper only, eliminating the need of any other material and used directly without any further purification or modification steps. When comparisons were made between the performance of CAs used in this study and other studies based on CNTs and metal nanoparticles, the capacities reach $78.14 \mathrm{mg} / \mathrm{g}^{5}$ for cupric oxide nanoparticles toward ciprofloxacin and 153.08 $\mathrm{mg} / \mathrm{g}^{3}$ and $173.28^{2}$ for multiwalled CNTs toward amoxicillin and metronidazole, respectively. However, when natural-based adsorbents are considered, the performance of CAs can be considered rather well. For instance, capacities reach 41.58 $\mathrm{mg} / \mathrm{g}$ for the maize stalk biosorbent toward tetracycline, ${ }^{8} 48.28$ $\mathrm{mg} / \mathrm{g}$ for the rice husk biosorbent toward metronidazole, ${ }^{49}$ and 55.19 and $58.11 \mathrm{mg} / \mathrm{g}$ for azolla filiculoides toward tetracycline $^{50}$ and cephalexin, respectively. ${ }^{60}$

It was reported by Peng et al. that the amount of aromatic rings on antibiotics had an impact on the adsorption rate. ${ }^{51}$ In the article, they defined the hexagonal ring molecular structure as the $\pi$-ring and stated that as the number of the rings on antibiotics increased, the faster they were adsorbed on the carbon materials. In their study, they used four ring-containing tetracycline and ofloxacin, two ring-containing sulfadiazine, amoxicillin, and sulfamethazine, and single ring-containing sulfamethoxazole and cefalexin. Although their results were in good agreement with their claim, there were some exceptions such that for some cases, single ring-containing antibiotics were adsorbed faster than the double ring ones. In our study, to observe the effect of the number of rings on the molecules to the adsorption rate, Hyg B (3 rings), Gen (3 rings), and Van ( 7 rings) were chosen. Despite the number of rings being the same for Hyg B and Gen, the adsorption rate of Gen was found to be almost half of that of Hyg B. For Van, however, the rate was much higher. Even though $\pi-\pi$ interactions do not act in this system, increased amount of aromatic rings did result in better adsorption. In the aforementioned study by Peng et al., the mean values for the adsorption capacities of the graphene, first biochar, and second biochar were found as 190.3, 105.7, and $199.0 \mu \mathrm{g} / \mathrm{g}$, respectively. Even though the synthesis and purification of graphene are rather complex and difficult, in this example, the adsorption capacity of the simply produced biochar from bamboo was much higher. Compared to this study, CAs used in our study are found to have much larger adsorption capacity with a much simpler production route, moreover by recycling the waste papers. Compared to the abovementioned study with $\mathrm{GH}$ and $\mathrm{GA},{ }^{43}$ the aerogels in our study found to have up to 2-2.5 times more adsorption capacity than the GAs. Although CA material does not exhibit superior adsorption behaviors, it is quite comparable with, and sometimes better than, carbon xerogels, ${ }^{20} \mathrm{CNTs},{ }^{20}$ chemically prepared carbon, ${ }^{21}$ and $\mathrm{GO} /$ calcium alginate fibers. ${ }^{23}$ It also showed better performance compared to various other adsorbents provided in the literature; for instance, in studies conducted with tetracycline, the adsorption capacities of GOfunctionalized magnetic nanoparticles ${ }^{52}$ and modified biochar $^{53}$ were found to be $39.1 \mathrm{mg} / \mathrm{g}$ and $17 \mathrm{mg} / \mathrm{g}$, respectively.

A rather new study on the removal of ampicillin from wastewater showed a comparison between the performances of liquid nitrogen-treated (CM1) and -untreated (CM2) carbon materials. ${ }^{54}$ The adsorption capacities of CM1 with 550.52 $\mathrm{m}^{2} / \mathrm{g}$ and CM2 with $422.93 \mathrm{~m}^{2} / \mathrm{g}$ BET surface areas were found to be 206.00 and $178.423 \mathrm{mg} / \mathrm{g}$, respectively. In our study, the BET surface area of the CA was found as $104.2 \mathrm{~m}^{2} /$ $\mathrm{g}$, which is almost 4-5 times smaller than that of CM1 and CM2, whereas when the adsorption capacities are compared, there is only up to 2 times difference between them. Despite the specific surface area being believed to be the main factor affecting the adsorption capacity, ${ }^{55}$ CAs with a much less surface area still resulted in comparably high adsorption capacity. Their kinetic and isotherm models are in good agreement without findings, which are the pseudo-secondorder kinetic and Langmuir models. Finally, a very recently published paper included the comparison of terramycin and levofloxacin adsorption on CAs and magnetic CAs. ${ }^{56}$ In the study, resorcinol and formaldehyde were employed as carbon sources and aerogel network, and the specific surfaces areas found for each material were extremely high. The kinetic studies were found to fit the pseudo-second-order kinetic model and high adsorption capacity was obtained. Because of this highly effective adsorption, the adsorption mechanism between terramycin and the CA was suggested to be resulting from $\pi-\pi$ interactions, although there was no graphene-like structure.

\section{CONCLUSIONS}

In this study, CAs were synthesized from waste papers and their adsorption behaviors toward three antibiotics were investigated. Those three antibiotics were selected from aminoglycoside and glycopeptide families rather than commonly studied sulphonamides, macrolides, fluoroquinolones, or tetracyclines. It was reported earlier that as the number of the rings on antibiotics increases, the faster they are adsorbed on the carbon materials. Although the amount of the benzene rings in Hyg B and Gen was the same, the adsorption rate of Gen was much slower. On the other hand, for Van, the rate was much higher as expected. This behavior is believed to be irrelevant to $\pi-\pi$ interactions. Therefore, even though the adsorbent does not have a graphene-like structure, the number of aromatic rings might still have an effect on the adsorption rate. For all three antibiotics, the adsorption behavior fits the Langmuir model, which is a quite common finding in many carbon adsorbent-based antibiotic adsorption studies. As a result of the kinetic studies, interaction between the surface of the CAs and all three antibiotics was found to fit the pseudosecond-order kinetic model, which is also in good agreement with many other studies. The adsorption capacities were found as $104.16,81.30$, and $107.52 \mathrm{mg} / \mathrm{g}$ for Hyg B, Gen, and Van, respectively. Various studies on this field showed that graphene-based structures resulted in better adsorption 
a)

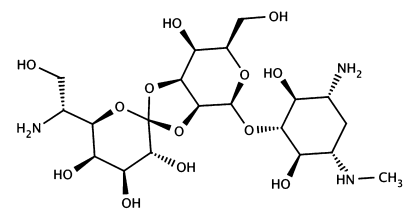

b)

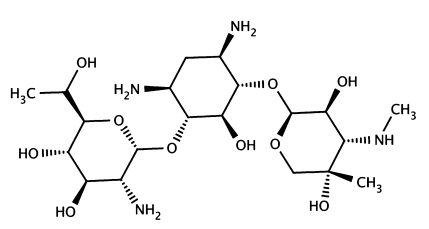

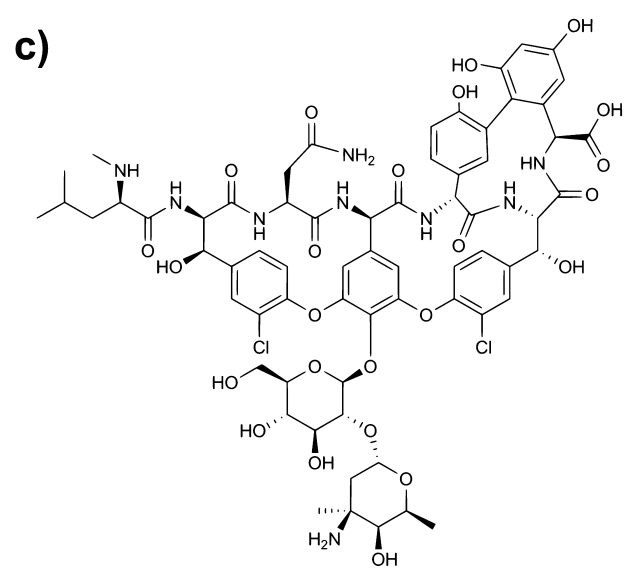

Figure 3. Chemical structures of antibiotics used in this study: (a) Hyg B, (b) Gen, and (c) Van.

capacities; however, one major drawback is their complex synthesis and sophisticated purification steps. The production of CAs by recycling the waste paper, within the scope of this study, is safe, facile, and cost-efficient which makes these green adsorbents a good candidate for the removal of antibiotics from water resources. To the best of our knowledge, this study represents the first antibiotic adsorption study based on CAs obtained from waste paper.

\section{MATERIALS AND METHODS}

4.1. Materials. Hyg B solution $(50 \mathrm{mg} / \mathrm{mL})$ and $\mathrm{Gen}$ solution $(10 \mathrm{mg} / \mathrm{mL})$ were purchased from Capricorn Scientific, Germany. Van hydrochloride (250 mg) was purchased from Santa Cruz Biotechnology, USA. The chemical structures of the antibiotics are provided in Figure 3.

4.2. Preparation and Characterization of CAs. The preparation of the CAs included three major stages: pulp preparation from a biomass source, freeze-drying, and pyrolysis. In detail, $0.06 \mathrm{~g}$ of waste papers was soaked in 40 $\mathrm{mL}$ of distilled water for $24 \mathrm{~h}$ in a falcon tube. Then, $10 \mathrm{~mL}$ of $10 \% \mathrm{HCl}$ was added to the falcon tube. When papers are exposed to $\mathrm{HCl} / \mathrm{H}_{2} \mathrm{O}$, the hydrolysis reaction occurs. The protonation of the glycoside bond leads to the cleavage and as a result, cellulose polymer fragments are obtained. Accordingly, papers were then broken down into strands of cellulose through the $\mathrm{HCl}$ treatment. After $12 \mathrm{~h}$, cellulose fragments were centrifuged to wash away the $\mathrm{HCl}$. This process was repeated 4 times at a speed of $6000 \mathrm{rpm}$. Next, they were carefully placed in Petri dishes and left to dry at $60{ }^{\circ} \mathrm{C}$ for at least $2 \mathrm{~h}$. Then, the dried cellulose fragments were wetted again by the addition of $20 \mathrm{~mL}$ of distilled water and magnetically stirred vigorously without heating for 2 days, followed by mechanical stirring at $1000 \mathrm{rpm}$ for 1 day. Because of strong agitation under both magnetic and mechanical stirring, they formed pulps. Then, pulps were collected and placed in a $-86{ }^{\circ} \mathrm{C}$ freezer and let to stay there for 1 day. The frozen pulps were lyophilized (freeze-dried) and finally pyrolized at $850{ }^{\circ} \mathrm{C}$ (with a heating rate of $5{ }^{\circ} \mathrm{C} / \mathrm{min}$ ) for 3 $\mathrm{h}$ at a low pressure (0.1 atm) under an argon atmosphere. Black and featherweight CAs were obtained (Figure S1). Using different containers, shapes and sizes of these aerogels can be controlled. For instance, in this study, we used a 24-well plate and filled each well completely (Figure 4).
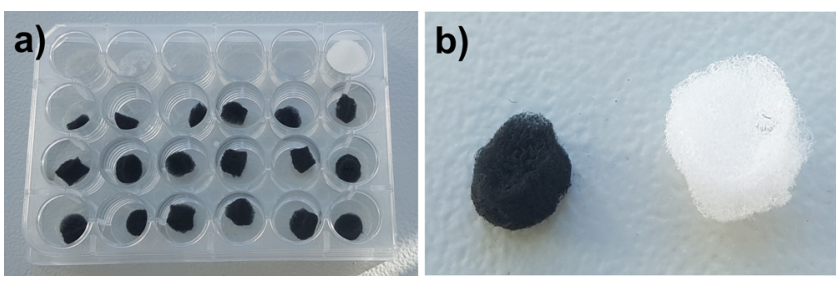

Figure 4. (a) Production of CAs in a 24-well-plate and (b) size comparison of the CA structure before (white) and after (black) pyrolysis.

The CAs were coated with gold-palladium, and microstructural morphology of the prepared materials was investigated using SEM (Quanta 400F field emission SEM, Germany). TEM imaging was performed using a CTEM FEI, Tecnai $G^{2}$ (The Netherlands). For this purpose, a small piece of carbon material was dispersed in ethanol and deposited on a carbon-coated copper grid. The surface chemical composition was studied with XPS (PHI 5000 Versa Probe, Japan). The quantity of elements ( $\mathrm{C}, \mathrm{H}, \mathrm{N}$, and $\mathrm{S}$ ) in the produced materials was determined using a CHNS-932 elemental analyzer (Leco, USA). To evaluate the $3 \mathrm{D}$ microstructural properties of the samples, a micro-computerized tomography $(\mu$-CT) (Bruker SKYSCAN 1172, USA) was employed. Finally, the BET surface area calculations were performed using an Autosorb 6B surface area analyzer (Quantochrome Co., U.K.).

4.3. Parameters and Setup for the Adsorption Studies. Antibiotic solutions with concentrations ranging between $0.01-0.1 \mathrm{mg} / \mathrm{mL}$ (for Gen and Van) and $0.1-1 \mathrm{mg} /$ $\mathrm{mL}$ (for Hyg B) were prepared either by dissolving or diluting 
in DI water. Then, their UV absorbance values were recorded, and concentration versus absorbance values were drawn as the calibration curves and the $R^{2}$ values were obtained. According to the graphs, error percentages were calculated, and concentrations with the least error were chosen for the $\mathrm{pH}$, time, and concentration scan studies for each antibiotic.

For the $\mathrm{pH}$ studies, the range was selected as 3-9 for Hyg B and Gen and 2-8 for Van. A total of $10 \mathrm{~mL}$ of antibiotic solutions $(0.4 \mathrm{mg} / \mathrm{mL}, 0.04 \mathrm{mg} / \mathrm{mL}$, and $0.04 \mathrm{mg} / \mathrm{mL}$ for $\mathrm{Hyg}$ $\mathrm{B}$, Gen, and Van, respectively) and $0.0006 \mathrm{~g}$ of CAs were treated for $3 \mathrm{~h}$ at each $\mathrm{pH}$ value. For the time studies, antibiotics and aerogels were treated for a time range of $0-180$ $\mathrm{min}$. Next, $10 \mathrm{~mL}$ of solutions was incubated with $0.0006 \mathrm{~g}$ of CA. At certain time points, samples were taken and their absorbance values were recorded. During time studies, $\mathrm{pH}$ was kept constant at 7, 6, and 3 for Hyg B, Gen, and Van, respectively, at which the highest binding capacities were obtained during $\mathrm{pH}$ studies. Finally, for the concentration studies, the following concentration ranges were employed: $0.2-0.8 \mathrm{mg} / \mathrm{mL}$ for Hyg B, $0.02-0.2 \mathrm{mg} / \mathrm{mL}$ for Gen, and $0.02-0.2 \mathrm{mg} / \mathrm{mL}$ for Van.

Initially, the UV absorbance values at the beginning of each experiment set were measured and recorded as " $A_{\mathrm{i}}$ ". The absorbance values after each experiment were recorded as " $A_{\mathrm{f}}$ ". $C_{\mathrm{i}}$ and $C_{\mathrm{f}}$ values were calculated from eq 1 .

$$
C_{\mathrm{i}}=\frac{A_{\mathrm{i}}-n}{m} \text { and } C_{\mathrm{f}}=\frac{A_{\mathrm{f}}-n}{m}
$$

where $n$ and $m$ are constants derived from the original form of the equation of the graph $(y=m x+n)$. From the $C_{\mathrm{i}}$ and $C_{\mathrm{f}}$ values obtained, binding capacities $(Q)$ were calculated using eq 2.

$$
Q=\frac{\left(C_{\mathrm{i}}-C_{\mathrm{f}}\right) \cdot V}{m}
$$

where $V$ is the volume and $m$ is the mass. Curves for binding capacity values versus concentrations were drawn for each sample.

4.3.1. Adsorption Isotherms. Adsorption isotherms define the connection between the adsorbate concentration in the equilibrium solution and the amount of the adsorbate in the solid phase that is adsorbed. The adsorption process continues until equilibrium is established between the adsorbate concentration accumulated on the adsorbent and the adsorbate concentration left in the solution and this equilibrium is explained by the adsorption isotherms. Langmuir, Freundlich, Temkin, and $\mathrm{D}-\mathrm{R}$ adsorption models are applied to define the interaction between the adsorbed molecules and the adsorbent.

The Langmuir adsorption isotherm is defined using eq 3. This isotherm assumes that molecules interact with regions that only accept single-molecule adsorption at a time and that their energies are equal, excluding any type of interaction between molecules and neighboring regions.

$$
Q=\frac{Q_{\max } b C_{\mathrm{e}}}{\left(1+b C_{\mathrm{e}}\right)}
$$

Here, $Q(\mathrm{mg} / \mathrm{g})$ is the amount of the antibiotic adsorbed on the adsorbent, $C_{\mathrm{e}}(\mathrm{mg} / \mathrm{mL})$ is the concentration of the antibiotic at equilibrium, $b(\mathrm{~mL} / \mathrm{mg})$ is the Langmuir constant, and $Q_{\max }(\mathrm{mg} / \mathrm{g})$ is the maximum adsorption capacity. When the equation is linearized, the following equation is obtained

$$
\frac{1}{Q_{\mathrm{e}}}=\frac{1}{Q_{\max } \cdot b} \frac{1}{C_{\mathrm{e}}}+\frac{1}{Q_{\max }}
$$

for which the point cutting the $y$ axis for the graph $1 / C_{\mathrm{e}}$ versus $1 / Q$ gives $1 / Q_{\max }$ and the slope of the graph gives $\frac{1}{Q_{\max }} b$.

The Freundlich adsorption isotherm assumes that the adsorption of the adsorbate to the adsorbent depends highly upon the neighboring regions being whether full or not. The Freundlich equation is provided in eq 5.

$$
Q_{\mathrm{eq}}=K_{\mathrm{f}} C_{\mathrm{eq}}{ }^{1 / n}
$$

Here, $Q_{\text {eq }}(\mathrm{mg} / \mathrm{g})$ represents the adsorption amount and $C_{\mathrm{e}}$ $(\mathrm{mg} / \mathrm{mL})$ is the antibiotic concentration at equilibrium. $K_{\mathrm{f}}$ and $1 / n$ are the Freundlich constants, in detail, the Freundlich exponent and the Freundlich slope, respectively. By taking the $\log$ of each side, eq 6 can be obtained.

$$
\ln Q_{\mathrm{eq}}=\ln K_{\mathrm{f}}+\frac{1}{n} \ln C_{\mathrm{eq}}
$$

The experimental findings were adapted to the Freundlich model, and the graph of $\ln C_{\mathrm{eq}}$ versus $\ln Q_{\mathrm{eq}}$ was drawn. The adsorption constants were calculated from the cutting points and the slope.

For the systems where the adsorption curve depends on the porous surface of the adsorbent, the $\mathrm{D}-\mathrm{R}$ isotherm is used widely. With the $\mathrm{D}-\mathrm{R}$ model, it can be determined whether the adsorption mechanism is physical or chemical. Equation 7 is used for the $\mathrm{D}-\mathrm{R}$ isotherm model.

$$
\ln Q_{\mathrm{e}}=\ln Q_{\mathrm{m}}-\beta \varepsilon^{2}
$$

Here, $Q_{e}$ and $Q_{m}$ represent the adsorbed antibiotics and the maximum adsorption capacity in $\mathrm{mol} / \mathrm{g}$, respectively. $\beta$ is the constant depending on adsorption energy in $\mathrm{mol}^{2} / \mathrm{J}^{2}$ and $\varepsilon$ is the Polanyi potential and is found from eq 8 .

$$
\beta=R T \ln \left(1+\frac{1}{C_{e}}\right)
$$

When the plot of $\ln Q_{\mathrm{e}}$ versus $\varepsilon^{2}$ is drawn, the slope yields $\beta$ and the intercept point of the $y$ axis yields $\ln Q_{\mathrm{m}}$. Using the constant $\beta$, average adsorption energy can be calculated using eq $9 .{ }^{57}$

$$
E=\sqrt{\frac{1}{2 \beta}}
$$

If the energy is found to be between 8 and $16 \mathrm{~kJ} \mathrm{~mol}^{-1}$, the adsorption mechanism can be related with chemical ion exchange; if it is greater than $16 \mathrm{~kJ} \mathrm{~mol}^{-1}$, the process is driven by chemical interactions and classified as chemisorption, whereas if the energy is found to be smaller than $8 \mathrm{~kJ} \mathrm{~mol}^{-1}$, this interaction would be physical and classified as physisorption. $^{41,58}$

As an assumption of linear decrease in the adsorption energy due to interactions between the adsorbate and adsorbent, the linear Temkin isotherm equation was derived (eq 10). In this model, as the active centers on the adsorbent are filled, it is assumed that the adsorption energy decreases linearly.

$$
Q_{\mathrm{e}}=B \ln K_{\mathrm{t}}+B \ln C_{\mathrm{e}}
$$

Here, $B$ is represented with $R T / b$ where $b$ is the Temkin constant in $\mathrm{J} / \mathrm{mol}$ and is related with the adsorption heat. ${ }^{59}$ 
4.3.2. Adsorption Kinetics. The rate control mechanism depends on three possible steps during the adsorption process. First one is the mass transfer to the outer surface at the early stages of the adsorption or film diffusion. This is followed by the reaction or constant rate step, forming the second one. At the third and the last step, diffusion toward the inner parts of the pores takes place where the adsorption amount is significantly decreased. These rate control mechanisms are explained with the pseudo-first-order and the pseudo-secondorder kinetic models.

If the adsorption rate-determining step is based on the diffusion of the analyte to the surface of the adsorbent, the system fits the pseudo-first-order model. If the adsorption ratedetermining step is based on the interaction between the analyte and the adsorbent, the system fits the pseudo-secondorder model. The first case is called a diffusion-controlled process and the second one is referred to as chemisorption. The treatment and exposure times are important to understand the steps affecting adsorption rates. The mechanisms controlling the adsorption process are mass transfer and chemical reactions. In the determination of these mechanisms, pseudo-first-order and pseudo-second-order models were applied to the experimental data. Concentrations measured were assumed to be equal to the adsorbents' surface concentrations. The pseudo-first-order equation is quite commonly used in the adsorption of a solute in a solution (eq 11).

$$
\frac{\mathrm{d} q_{t}}{\mathrm{~d} t}=k_{1}\left(q_{\mathrm{eq}}-q_{t}\right)
$$

Here, $k_{1}(1 / \mathrm{min})$ is the pseudo-first-order adsorption rate constant, $q_{\mathrm{eq}}(\mathrm{mg} / \mathrm{g})$ and $q_{t}(\mathrm{mg} / \mathrm{g})$ are the adsorbed antibiotic amounts at equilibrium and at $t$, respectively. Taking the integral with boundary conditions of $t=0 \mathrm{~min}, q_{t}=0$, and $t=t$ min, $q_{t}=q_{t}$ would lead to eq 12

$$
\log \left(\frac{q_{\mathrm{eq}}}{q_{\mathrm{eq}}-q_{t}}\right)=\frac{k_{1} t}{2.303}
$$

When this equality is linearized, eq 13 can be obtained.

$$
\log \left(\frac{q_{\mathrm{eq}}}{q_{t}}\right)=\log \left(q_{\mathrm{eq}}\right)-\frac{k_{1} t}{2.303}
$$

The linearity of the graph of $t$ versus $\log \left(q_{\text {eq }}\right)$ shows the applicability of the kinetic model.

The pseudo-second-order equation based on equilibrium capacity of the adsorption is given in eq 14 .

$$
\frac{\mathrm{d} q_{t}}{\mathrm{~d} t}=k_{2}\left(q_{\mathrm{eq}}-q_{t}\right)^{2}
$$

Here, $k_{2}(\mathrm{~g} / \mathrm{mg} \cdot \mathrm{min})$ is the pseudo-second-order adsorption rate constant. Similarly, taking the integral with boundary conditions of $t=0 \mathrm{~min}, q_{t}=0$, and $t=t \mathrm{~min}, q_{t}=q_{t}$ would lead to eq 15

$$
\frac{1}{q_{\mathrm{eq}}-q_{t}}=\frac{1}{q_{\mathrm{eq}}}+k_{2} t
$$

The linearized version of this equation is given in eq 16 .

$$
\frac{t}{q_{t}}=\frac{1}{k_{2} q_{\mathrm{eq}}{ }^{2}}+\frac{1}{q_{\mathrm{eq}}} t
$$

For the second-order kinetic model to be applicable, the graph of $t$ versus $t / q_{t}$ should be linear. The rate constant $\left(k_{2}\right)$ and equilibrium adsorption $\left(q_{\text {eq }}\right)$ should be obtained from the cutting point and the slope, respectively.

Adsorbate molecules usually moved from the solution to solid phase through the IPD process, which is the ratedetermining step. IPD probability can be explained using the IPD model. ${ }^{60}$

To test whether the adsorption study fits this model, eq 17 is employed.

$$
q_{t}=k_{\mathrm{i}} t^{0.5}+C
$$

Here, $k_{\mathrm{i}}$ is the IPD rate constant and $C$ is the boundary layer thickness. The graph of $q_{t}$ versus $t^{0.5}$ is drawn. For this model to be valid, the slope of the obtained curve should yield a straight line.

\section{ASSOCIATED CONTENT}

\section{SI Supporting Information}

The Supporting Information is available free of charge at https://pubs.acs.org/doi/10.1021/acsomega.0c01479.

Real images of CAs before and after pyrolysis for size comparison; XPS spectrum of CAs; nitrogen, carbon, hydrogen, and sulfur percentages in produced CAs; $\mu$ CT data; pseudo-first-order and pseudo-second-order kinetic study graphs; and IPD graphs (PDF)

\section{AUTHOR INFORMATION}

\section{Corresponding Author}

Halil Murat Aydin - Bioengineering Division, Institute of Science \& Center for Bioengineering, Hacettepe University, Ankara 06800, Turkey; @orcid.org/0000-0003-4107-4324; Phone: (+90) 31222705 85; Email: hmaydin@ hacettepe.edu.tr

\section{Authors}

Gülgün Aylaz - Nanotechnology and Nanomedicine Division, Institute of Science, Hacettepe University, Ankara 06800, Turkey

Meltem Okan - Micro and Nanotechnology Division, Graduate School of Natural and Applied Sciences, Middle East Technical University, Ankara 06800, Turkey

Memed Duman - Nanotechnology and Nanomedicine Division, Institute of Science, Hacettepe University, Ankara 06800, Turkey

Complete contact information is available at: https://pubs.acs.org/10.1021/acsomega.0c01479

\section{Author Contributions}

G.A. and M.O. contributed equally to this work. All authors have given approval to the final version of the manuscript.

\section{Funding}

No funding was received in the making of this study.

\section{Notes}

The authors declare no competing financial interest. 


\section{ACKNOWLEDGMENTS}

The authors would like to thank Dr. M. Andaç for helping with the calculations and Dr. A. Tevlek for the contributions during the optimization of CA synthesis.

\section{ABBREVIATIONS}

CAs, carbon aerogels; Hyg B, hygromycin B; Gen, gentamicin; Van, vancomycin; D-R, Dubinin-Radushkevich; IPD, intraparticle diffusion

\section{REFERENCES}

(1) Okan, M.; Sari, E.; Duman, M. Molecularly imprinted polymer based micromechanical cantilever sensor system for the selective determination of ciprofloxacin. Biosens. Bioelectron. 2017, 88, 258264.

(2) Azarpira, H.; Mahdavi, Y.; Khaleghi, O.; Balarak, D. Thermodynamic Studies on the Removal of Metronidazole Antibiotic by Multi-Walled Carbon Nanotubes. Der Pharm. Lett. 2016, 8, 107113.

(3) Balarak, D.; Mostafapour, F.; Bazrafshan, E.; Saleh, T. A. Studies on the Adsorption of Amoxicillin on Multi-Wall Carbon Nanotubes. Water Sci. Technol. 2017, 75, 1599-1606.

(4) Miranda, C. D.; Zemelman, R. Antimicrobial Multiresistance in Bacteria Isolated from Freshwater Chilean Salmon Farms. Sci. Total Environ. 2002, 293, 207-218.

(5) Ahmadi, S.; Banach, A.; Mostafapour, F. K.; Balarak, D. Study Survey of Cupric Oxide Nanoparticles in Removal Efficiency of Ciprofloxacin Antibiotic from Aqueous Solution: Adsorption Isotherm Study. Desalin. Water Treat. 2017, 89, 297-303.

(6) Kuhn, J.; Aylaz, G.; Sari, E.; Marco, M.; Yiu, H. H. P.; Duman, M. Selective Binding of Antibiotics Using Magnetic Molecular Imprint Polymer (MMIP) Networks Prepared from Vinyl-Functionalized Magnetic Nanoparticles. J. Hazard. Mater. 2020, 387, 121709.

(7) Okan, M.; Duman, M. Functional Polymeric Nanoparticle Decorated Microcantilever Sensor for Specific Detection of Erythromycin. Sens. Actuators, B 2018, 256, 325-333.

(8) Balarak, D.; Mostafapour, F. K.; Azarpira, H. Adsorption Isotherm Studies of Tetracycline Antibiotics from Aqueous Solutions by Maize Stalks as a Cheap Biosorbent. Int. J. Pharm. Technol. 2016, 8, 16664-16675.

(9) Luangtongkum, T.; Morishita, T. Y.; Ison, A. J.; Huang, S.; McDermott, P. F.; Zhang, Q. Effect of Conventional and Organic Production Practices on the Prevalence and Antimicrobial Resistance of Campylobacter Spp. in Poultry. Appl. Environ. Microbiol. 2006, 72, 3600-3607.

(10) Humphries, R. M.; Linscott, A. J. Laboratory Diagnosis of Bacterial Gastroenteritis. Clin. Microbiol. Rev. 2015, 28, 3-31.

(11) Bonten, M. J.; Willems, R.; Weinstein, R. A. VancomycinResistant Enterococci: Why Are They Here, and Where Do They Come From? Lancet Infect. Dis. 2001, 1, 314-325.

(12) Kraemer, S. A.; Ramachandran, A.; Perron, G. G. Antibiotic Pollution in the Environment: From Microbial Ecology to Public Policy. Microorganisms 2019, 7, 180.

(13) Koyuncu, I.; Arikan, O. A.; Wiesner, M. R.; Rice, C. Removal of Hormones and Antibiotics by Nanofiltration Membranes. J. Membr. Sci. 2008, 309, 94-101.

(14) Košutić, K.; Dolar, D.; Ašperger, D.; Kunst, B. Removal of Antibiotics from a Model Wastewater by RO/NF Membranes. Sep. Purif. Technol. 2007, 53, 244-249.

(15) Chelliapan, S.; Wilby, T.; Sallis, P. J. Performance of an UpFlow Anaerobic Stage Reactor (UASR) in the Treatment of Pharmaceutical Wastewater Containing Macrolide Antibiotics. Water Res. 2006, 40, 507-516.

(16) Arslan-Alaton, I.; Dogruel, S. Pre-Treatment of Penicillin Formulation Effluent by Advanced Oxidation Processes. J. Hazard. Mater. 2004, 112, 105-113.
(17) Choi, K.-J.; Son, H.-J.; Kim, S.-H. Ionic Treatment for Removal of Sulfonamide and Tetracycline Classes of Antibiotic. Sci. Total Environ. 2007, 387, 247-256.

(18) Chen, W.-R.; Huang, C.-H. Adsorption and Transformation of Tetracycline Antibiotics with Aluminum Oxide. Chemosphere 2010, 79, 779-785.

(19) Zhuang, Y.; Yu, F.; Ma, J.; Chen, J. Enhanced Adsorption Removal of Antibiotics from Aqueous Solutions by Modified Alginate/Graphene Double Network Porous Hydrogel. J. Colloid Interface Sci. 2017, 507, 250.

(20) Zhang, Z.; Xiao, F.; Guo, Y.; Wang, S.; Liu, Y. One-Pot SelfAssembled Three-Dimensional TiO2-Graphene Hydrogel with Improved Adsorption Capacities and Photocatalytic and Electrochemical Activities. ACS Appl. Mater. Interfaces 2013, 5, 2227-2233.

(21) Fan, Z.; Wang, K.; Wei, T.; Yan, J.; Song, L.; Shao, B. An Environmentally Friendly and Efficient Route for the Reduction of Graphene Oxide by Aluminum Powder. Carbon 2010, 48, 16861689.

(22) Stankovich, S.; Dikin, D. A.; Piner, R. D.; Kohlhaas, K. A.; Kleinhammes, A.; Jia, Y.; Wu, Y.; Nguyen, S. T.; Ruoff, R. S. Synthesis of Graphene-Based Nanosheets via Chemical Reduction of Exfoliated Graphite Oxide. Carbon 2007, 45, 1558-1565.

(23) Ma, J.; Yu, F.; Zhou, L.; Jin, L.; Yang, M.; Luan, J.; Tang, Y.; Fan, H.; Yuan, Z.; Chen, J. Enhanced Adsorptive Removal of Methyl Orange and Methylene Blue from Aqueous Solution by AlkaliActivated Multiwalled Carbon Nanotubes. ACS Appl. Mater. Interfaces 2012, 4, 5749-5760.

(24) Shi, S.; Fan, Y.; Huang, Y. Facile Low Temperature Hydrothermal Synthesis of Magnetic Mesoporous Carbon Nanocomposite for Adsorption Removal of Ciprofloxacin Antibiotics. Ind. Eng. Chem. Res. 2013, 52, 2604-2612.

(25) Xiong, W.; Zeng, G.; Yang, Z.; Zhou, Y.; Zhang, C.; Cheng, M.; Liu, Y.; Hu, L.; Wan, J.; Zhou, C.; Xu, R.; Li, X. Adsorption of Tetracycline Antibiotics from Aqueous Solutions on Nanocomposite Multi-Walled Carbon Nanotube Functionalized MIL-53(Fe) as New Adsorbent. Sci. Total Environ. 2018, 627, 235-244.

(26) Mousavi, S. A.; Janjani, H. Antibiotics adsorption from aqueous solutions using carbon nanotubes: a systematic review. Toxin Rev. 2020, 39, 87.

(27) Worsley, M. A.; Baumann, T. F. Carbon Aerogels. Handbook of Sol-Gel Science and Technology; Springer International Publishing Switzerland, 2016; pp 1-36.

(28) Somanathan, T.; Prasad, K.; Ostrikov, K.; Saravanan, A.; Krishna, V. Graphene Oxide Synthesis from Agro Waste. Nanomaterials 2015, 5, 826-834.

(29) Marcano, D. C.; Kosynkin, D. V.; Berlin, J. M.; Sinitskii, A.; Sun, Z.; Slesarev, A.; Alemany, L. B.; Lu, W.; Tour, J. M. Improved Synthesis of Graphene Oxide. ACS Nano 2010, 4, 4806-4814.

(30) Zhang, Z.; Sèbe, G.; Rentsch, D.; Zimmermann, T.; Tingaut, P. Ultralightweight and Flexible Silylated Nanocellulose Sponges for the Selective Removal of Oil from Water. Chem. Mater. 2014, 26, 26592668.

(31) Li, L.; Li, B.; Sun, H.; Zhang, J. Compressible and Conductive Carbon Aerogels from Waste Paper with Exceptional Performance for Oil/Water Separation. J. Mater. Chem. A 2017, 5, 14858-14864.

(32) Bi, H.; Huang, X.; Wu, X.; Cao, X.; Tan, C.; Yin, Z.; Lu, X.; Sun, L.; Zhang, H. Carbon Microbelt Aerogel Prepared by Waste Paper: An Efficient and Recyclable Sorbent for Oils and Organic Solvents. Small 2014, 10, 3544-3550.

(33) Nguyen, S. T.; Feng, J.; Le, N. T.; Le, A. T. T.; Hoang, N.; Tan, V. B. C.; Duong, H. M. Cellulose Aerogel from Paper Waste for Crude Oil Spill Cleaning. Ind. Eng. Chem. Res. 2013, 52, 18386.

(34) Han, S.; Sun, Q.; Zheng, H.; Li, J.; Jin, C. Green and Facile Fabrication of Carbon Aerogels from Cellulose-Based Waste Newspaper for Solving Organic Pollution. Carbohydr. Polym. 2016, 136, 95-100.

(35) Beckline, M.; Yujun, S.; Eric, Z.; Kato, M. S. Paper Consumption and Environmental Impact in an Emerging Economy. J. Energy, Environ. Chem. Eng. 2016, 1, 13-18. 
(36) Wu, Z.-Y.; Li, C.; Liang, H.-W.; Chen, J.-F.; Yu, S.-H. Ultralight, Flexible, and Fire-Resistant Carbon Nanofiber Aerogels from Bacterial Cellulose. Angew. Chem., Int. Ed. 2013, 52, 2925-2929.

(37) Baudoux, P.; Bles, N.; Lemaire, S.; Mingeot-Leclercq, M.-P.; Tulkens, P. M.; Van Bambeke, F. Combined Effect of PH and Concentration on the Activities of Gentamicin and Oxacillin against Staphylococcus Aureus in Pharmacodynamic Models of Extracellular and Intracellular Infections. J. Antimicrob. Chemother. 2007, 59, 246253.

(38) Abdulmunim, Z.; Jabbar, R. N.; Al-Shaibani, A. B. Studying the Optimum Conditions of Hygromycin B Production and Detect Their Toxicity. J. Univ. Babylon 2018, 26, 119-130.

(39) Pauwels, J.; Spriet, I.; Fu, X.; von Winckelmann, S.; Willems, L.; Hoogmartens, J.; Van Schepdael, A. Chemical Stability and Compatibility Study of Vancomycin for Administration by Continuous Infusion in Intensive Care Units. J. Liq. Chromatogr. Relat. Technol. 2011, 34, 1965-1975.

(40) Gautam, R. K.; Chattopadhyaya, M. C. Kinetics and Equilibrium Isotherm Modeling: Graphene-Based Nanomaterials for the Removal of Heavy Metals From Water. Nanomaterials for Wastewater Remediation; Elsevier, 2016; pp 79-105.

(41) Youssef, A. M.; El-Khouly, S. M.; El-Nabarawy, T. Removal of $\mathrm{Pb}$ (II) and $\mathrm{Cd}$ (II) From Aqueous Solution Using Oxidized Activated Carbons Developed From Pecan Shells. Carbon Lett. 2008, 9, 8-16.

(42) Alsawalha, M.; Rößner, F.; Novikova, L.; Bel'chinskaya, L. Acidity of Different Jordanian Clays Characterized by TPD-NH 3 and MBOH Conversion. World Acad. Sci. Eng. Technol. 2011, 5, 7-29.

(43) Ma, J.; Sun, Y.; Zhang, M.; Yang, M.; Gong, X.; Yu, F.; Zheng, J. Comparative Study of Graphene Hydrogels and Aerogels Reveals the Important Role of Buried Water in Pollutant Adsorption. Environ. Sci. Technol. 2017, 51, 12283-12292.

(44) Ma, J.; Yang, M.; Yu, F.; Zheng, J. Water-Enhanced Removal of Ciprofloxacin from Water by Porous Graphene Hydrogel. Sci. Rep. 2015, 5, 1-10.

(45) Moreno-Castilla, C. Adsorption of Organic Molecules from Aqueous Solutions on Carbon Materials. Carbon 2004, 42, 83-94.

(46) Keiluweit, M.; Kleber, M. Molecular-Level Interactions in Soils and Sediments: The Role of Aromatic $\pi$-Systems. Environ. Sci. Technol. 2009, 43, 3421-3429.

(47) Wang, J.; Chen, Z.; Chen, B. Adsorption of Polycyclic Aromatic Hydrocarbons by Graphene and Graphene Oxide Nanosheets. Environ. Sci. Technol. 2014, 48, 4817-4825.

(48) Smith, A. T.; LaChance, A. M.; Zeng, S.; Liu, B.; Sun, L. Synthesis, Properties, and Applications of Graphene Oxide/Reduced Grapheneoxide and Their Nanocomposites. Nano Mater. Sci. 2019, 1, 31-47.

(49) Azarpira, H.; Balarak, D. Rice Husk as a Biosorbent for Antibiotic Metronidazole Removal: Isotherm Studies and Model Validation. Int. J. ChemTech Res. 2016, 9, 566-573.

(50) Mahvi, A. H.; Mostafapour, F. K. Biosorption of Tetracycline from Aqueous Solution by Azolla Filiculoides: Equilibrium Kinetic and Thermodynamics Studies. Fresenius Environ. Bull. 2018, 27, 5759-5767.

(51) Peng, B.; Chen, L.; Que, C.; Yang, K.; Deng, F.; Deng, X.; Shi, G.; Xu, G.; Wu, M. Adsorption of Antibiotics on Graphene and Biochar in Aqueous Solutions Induced by $\pi-\pi$ Interactions. Sci. Rep. 2016, 6, 31920.

(52) Lin, Y.; Xu, S.; Li, J. Fast and Highly Efficient Tetracyclines Removal from Environmental Waters by Graphene Oxide Functionalized Magnetic Particles. Chem. Eng. J. 2013, 225, 679-685.

(53) Liu, P.; Liu, W.-J.; Jiang, H.; Chen, J.-J.; Li, W.-W.; Yu, H.-Q. Modification of Bio-Char Derived from Fast Pyrolysis of Biomass and Its Application in Removal of Tetracycline from Aqueous Solution. Bioresour. Technol. 2012, 121, 235-240.

(54) Wu, Y.; Liu, W.; Wang, Y.; Hu, X.; He, Z.; Chen, X.; Zhao, Y. Enhanced Removal of Antibiotic in Wastewater Using Liquid Nitrogen-Treated Carbon Material: Material Properties and Removal Mechanisms. Int. J. Environ. Res. Publ. Health 2018, 15, 2652.
(55) Yu, F.; Li, Y.; Han, S.; Ma, J. Adsorptive Removal of Antibiotics from Aqueous Solution Using Carbon Materials. Chemosphere 2016, $153,365-385$.

(56) Tian, X.; Liu, J.; Wang, Y.; Shi, F.; Shan, Z.; Zhou, J.; Liu, J. Adsorption of Antibiotics from Aqueous Solution by Different Aerogels. J. Non-Cryst. Solids 2019, 505, 72-78.

(57) Dubinin, M. M.; Radushkevich, L. V. The Equation of the Characteristic Curve of Activated Charcoal. Proceedings of the Academy of Sciences of the USSR: Physical Chemistry Section, 1947; Vol. 55, p 331.

(58) Lodeiro, P.; Barriada, J. L.; Herrero, R.; Sastre de Vicente, M. E. The marine macroalga Cystoseira baccata as biosorbent for cadmium(II) and lead(II) removal: Kinetic and equilibrium studies. Environ. Pollut. 2006, 142, 264-273.

(59) Nadeem, M.; Mahmood, A.; Shahid, S. A.; Shah, S. S.; Khalid, A. M.; McKay, G. Sorption of Lead from Aqueous Solution by Chemically Modified Carbon Adsorbents. J. Hazard. Mater. 2006, 138, 604-613.

(60) Balarak, D.; Azarpira, H.; Mostafapour, F. K. Study of the Adsorption Mechanisms of Cephalexin on to Azolla Filiculoides. Der Pharma Chem. 2016, 8, 114-121. 